\title{
Carotid blood flow distribution, haemodynamics and inotropic responses following calcitonin gene-related peptide in the pig
}

\author{
E. Marcel Van Gelderen *, Xiao Y. Du, Regien G. Schoemaker, Pramod R. Saxena * \\ Department of Pharmacology, Dutch Migraine Research Group, Cardiovascular Research Institute 'COEUR', Faculty of Medicine and Health \\ Sciences, Erasmus University Rotterdam, Postbox 1738, 3000 DR Rotterdam, Netherlands
}

Received 9 February 1995; revised 9 June 1995; accepted 13 June 1995

\begin{abstract}
The sensory neuropeptide, calcitonin gene-related peptide ( $\alpha$-CGRP), has been implicated in the pathogenesis of migraine headache. The present study aimed to evaluate the effects of intracarotid infusions of human $\alpha$-CGRP (10, 30 and 100 $\mathrm{pmol} / \mathrm{kg} \cdot \min ; n=8$ ), as compared to that of saline ( 4 times; $n=8$ ) on haemodynamics and blood flow distribution within the carotid circulation of the anaesthetized pig, using the radioactive microsphere method. Furthermore, the effects of antimigraine drugs, dihydroergotamine $(100 \mu \mathrm{g} / \mathrm{kg}$ i.v; $n=4)$ or sumatriptan $(300 \mu \mathrm{g} / \mathrm{kg}$ i.v.; $n=4)$, on these parameters were studied in the presence of the infusion of the highest concentration of human $\alpha$-CGRP. Additionally, putative positive inotropic responses to human $\alpha$-CGRP $\left(10^{-9}-10^{-7} \mathrm{M}\right)$ were investigated in porcine isolated atrial and ventricular trabeculae. Human $\alpha$-CGRP increased carotid artery blood flow and conductance dose-dependently, together with an enhancement in vascular pulsations. These effects were associated with a fall in systemic blood pressure with concomitant increases in heart rate and cardiac output. The increase in carotid blood flow was reflected by an increase in total capillary blood flow, predominantly to extracerebral tissues including the dura, whereas blood flow through arteriovenous anastomoses remained stable. Both dihydroergotamine and sumatriptan reduced carotid blood flow and its capillary fraction without affecting systemic vascular conductance. In tissues, these drugs reversed blood flow increases due to human $\alpha$-CGRP in most extracerebral tissues, but failed to reduce dural blood flow. In porcine isolated atrial and ventricular trabeculae, noradrenaline $\left(10^{-8}-10^{-5} \mathrm{M}\right)$ increased force of contraction in a concentration-dependent manner. In contrast, human $\alpha$-CGRP $\left(10^{-9}-10^{-7} \mathrm{M}\right)$ failed to increase force of contraction in atrial trabeculae $(n=6)$ and exerted only a moderate concentration-dependent positive inotropic effect in ventricular trabeculae ( $\sim 25 \%$ of the response to $10^{-5} \mathrm{M}$ noradrenaline, $n=10$ ). These data indicate that human $\alpha$-CGRP caused arteriolar dilatation together with a fall in blood pressure in the pig. The tachycardia may be reflex-mediated, but the peptide also exerts a moderate positive inotropic action on ventricular trabeculae. The fall in systemic arterial blood pressure and the marked increase in capillary blood flow most likely prevented the opening of arteriovenous anastomoses. Furthermore, the antimigraine drugs, dihydroergotamine and sumatriptan, were able to reverse blood flow changes induced by human $\alpha$-CGRP in the porcine carotid circulation.
\end{abstract}

Keywords: Arteriovenous anastomose; $\alpha$-CGRP (calcitonin gene-related peptide); Dihydroergotamine; Heart; Migraine, pig; Sumatriptan

\section{Introduction}

In spite of considerable debate concerning the precise mechanism, the pathogenesis of migraine is associated with dilatation of large (extra)cranial and arteriovenous anastomoses (Saxena, 1978; Drummond and Lance, 1988; Ferrari and Saxena, 1993). Recent obser-

\footnotetext{
* Corresponding author. Tel. $(+31) 10-4087537 / 7547$, fax $(+31)$ 10-436 6839, e-mail SAXENA@FARMA.FGG.EUR.NL.
}

vations in animals and humans have suggested that both calcitonin gene-related peptide (CGRP) and nitric oxide (NO) may act in concert in the vascular events observed during migraine attacks. The 37-amino acid peptide, CGRP, is abundantly present in sensory fibres, including fibres innervating the heart and trigeminal vascular system (Mulderry et al., 1985; Uddman et al., 1986; Suzuki et al., 1989). The peptide has been shown to be a potent vasodilator exerting differential regional haemodynamic effects (Brain et al., 1985; 
Franco-Cereceda et al., 1987; Gardiner et al., 1989). In migraineurs, elevated plasma levels of CGRP have been observed in the extracerebral circulation during headache (Goadsby et al., 1990) and antimigraine agents like dihydroergotamine and sumatriptan reduced elevated CGRP plasma levels in these patients, as well as in cats during trigeminal nerve stimulation (Goadsby and Edvinsson, 1993). Likewise, nitrovasodilators, which are generally thought to act by releasing NO (Ignarro, 1990), induce more pronounced headache (Olesen et al., 1993) and cranial artery dilatation in migraine patients than in normal subjects (Thomsen et al., 1993). Finally, nitrovasodilators increase blood flow through arteriovenous anastomoses in the carotid circulation of the pig (Van Gelderen et al., 1995) and may activate perivascular sensory nerves to release CGRP in cerebral as well as cutaneous microvessels (Wei et al., 1992; Holzer and Jočic, 1994).

The present study aimed to evaluate the effects of human $\alpha$-CGRP on haemodynamics and blood flow distribution within the carotid circulation of the pig, using the radioactive microsphere method. Since dihydroergotamine and sumatriptan have been shown to reduce carotid blood flow in pigs (Den Boer et al., 1992a,b), we also studied the effects of these two drugs on haemodynamics and carotid blood flow distribution during the infusion of human $\alpha$-CGRP.

Additionally, $\alpha$-CGRP has been shown to increase cardiac output (Lappe et al., 1987; Wang et al., 1989; Gardiner et al., 1991) and positive inotropic responses have been described in isolated atria of various species (Saito et al., 1987; Sigrist et al., 1986; Franco-Cereceda et al., 1987; Du et al., 1994). As preliminary experiments demonstrated an enhanced cardiac output following human $\alpha$-CGRP in pigs and as little is known about its putative inotropic effects in the pig heart, the effect of $\alpha$-CGRP was investigated further in porcine isolated atrial and ventricular trabeculae.

A preliminary account of some of the results was presented at the XIIth International Congress of Pharmacology (Van Gelderen and Saxena, 1994).

\section{Materials and methods}

The protocol of this study was submitted to and approved by the Institutional Committee for the use of animals.

\subsection{General (in vivo)}

After an overnight fast, 16 domestic pigs (Yorkshire $\times$ Landrace; $15-17 \mathrm{~kg}$ ) were anaesthetized with i.m. injection of ketamine $(25 \mathrm{mg} / \mathrm{kg})$ and midazolam $(0.3$ $\mathrm{mg} / \mathrm{kg}$ ). Following injection of thiopentone $(6 \mathrm{mg} / \mathrm{kg}$ ) in the middle ear vein, the animals were intubated and connected to a respirator (Bear 2E, BeMeds, Baar, Switzerland) for intermittent positive pressure ventilation. By adjusting oxygen supply, respiratory rate and tidal volume, arterial blood gas values were kept within the physiological range $\left(\mathrm{pH} 7.39-7.49 ; \mathrm{pCO}_{2} 37-44\right.$; $\mathrm{pO}_{2}$ 100-130). Anaesthesia was maintained by a continuous i.v. infusion with a mixture of fentanyl (18-38 $\mu \mathrm{g} / \mathrm{kg} / \mathrm{h})$ and thiopental $(6-12 \mathrm{mg} / \mathrm{kg} / \mathrm{h})$. This anaesthetic regimen was used to preserve the vasoconstrictor tone in cranial arteriovenous anastomoses that is necessary to study mechanisms involved in opening arteriovenous anastomoses (Den Boer et al., 1993). Due to differences in the sensitivity of individual animals, the infusion rate was adjusted in each animal using two criteria: (i) absence of blinking reflex, indicative of appropriate anaesthesia and (ii) venous oxygen saturation values below $60 \%$, indicative of low arteriovenous anastomotic blood flow.

A catheter was introduced into the aortic arch via the left femoral artery and was connected to a pressure transducer (Statham P23, Hato Rey, Puerto Rico) for the measurement of arterial blood pressure as well as withdrawal of blood samples to determine blood gases (ABL-510, Radiometer, Copenhagen, Denmark). Cardiac output, pulmonary arterial blood pressure and body temperature were measured with a $6 \mathrm{~F}-\mathrm{Swan}-\mathrm{Ganz}$ thermodilution catheter (Corodyn, Braun Melsungen, Melsungen, Germany) introduced into the pulmonary artery via the left femoral vein and connected to a cardiac output computer (WTI, Rotterdam, Netherlands) as well as to a pressure transducer. Mean arterial (MAP) and mean pulmonary artery (MPAP) pressures were calculated from the respective systolic (SBP) and diastolic (DBP) blood pressures as: MAP or $\mathrm{MPAP}=\mathrm{DBP}+(\mathrm{SBP}-\mathrm{DBP}) / 3$. Heart rate was recorded using a tachograph triggered from blood pressure signals as well as counted directly from these signals over a 30 -s recording interval. Systemic vascular conductance was calculated by dividing cardiac output by mean arterial pressure. The right common carotid artery was dissected free and the total carotid blood flow was measured with a flow probe (internal diameter: 2.5 or $3 \mathrm{~mm}$ ) connected to a sine-wave electromagnetic flow meter (Transflow 600-system, Skalar, Delft, Netherlands). Carotid vascular conductance was calculated by dividing carotid blood flow by mean arterial pressure and vascular pulse amplitude was calculated from the flow signals as the difference in systolic and diastolic blood flow values. Two hubless needles (external diameter $0.5 \mathrm{~mm}$ ), bent at right angles and connected to polyethylene tubing (internal diameter 0.5 $\mathrm{mm}$ ), were inserted into the common carotid artery against the direction of the blood flow for administration of radioactive microspheres or drugs. The right jugular vein was cannulated to collect venous blood samples to determine venous blood gases. All catheters 
were filled with a heparin sodium solution $(80 \mathrm{IU} / \mathrm{ml})$ to prevent blood clotting. During the experiment, physiological saline was infused to compensate for fluid loss and body temperature was kept between 37 and $38^{\circ} \mathrm{C}$.

\subsection{Distribution of common carotid artery blood flow}

As described extensively by Johnston and Saxena (1978), the distribution of common carotid artery blood flow was measured using repeated injections of radioactive microspheres (mean \pm S.D. diameter: $15 \pm 1$ $\mu \mathrm{m}$; NEN Company, Dreieich, Germany) with different labels $\left({ }^{141} \mathrm{Ce},{ }^{113} \mathrm{Sn},{ }^{103} \mathrm{Ru},{ }^{95} \mathrm{Nb}\right.$ or $\left.{ }^{46} \mathrm{Sc}\right)$. Briefly, a suspension of approximately 250000 microspheres was vortexed and injected into the common carotid artery at baseline and following the various treatments. Microspheres were injected against the direction of the blood flow to ensure uniform mixing. At the end of the experiment, the animals were killed and the heart, kidneys, lungs and the different intra-and extracranial tissues were dissected out, weighed and put in vials. The radioactivity in these vials was counted for $10 \mathrm{~min}$ in a $\gamma$-scintillation counter (Packard, Minaxi Autogamma 5000) using suitable windows for discriminating between the different isotopes. Radioactivity was counted in whole tissues, except in the case of bone, fat and skin, where aliquots (more than $50 \%$ of total weight) were analyzed.

Tissue (capillary) blood flow was calculated by multiplying the ratio of tissue and total radioactivity by total carotid blood flow at the time of injection, using a set of computer programs (Saxena et al., 1980). Since radioactivity was absent in the heart and kidneys, all radioactive microspheres reaching the venous side of the circulation had passed through arteriovenous anastomoses to be ultimately sieved in the lungs (see Johnston and Saxena, 1978; Saxena and Verdouw, 1982). Therefore, the amount of radioactivity in the lungs represents the arteriovenous anastomotic fraction of common carotid blood flow.

\subsection{Isolated atrial and ventricular trabeculae}

Cardiac tissues were obtained from pigs at the end of control (saline) experiments and atrial and ventricular trabeculae were set up for recording of contractions as described previously (Schoemaker et al., 1992; Du et al., 1994). Briefly, after excision, pieces of atrial and ventricular myocardium were placed in ice-chilled oxygenated Krebs buffer (composition in $\mathrm{mM}$ : $\mathrm{NaCl} 118$, $\mathrm{KCl} 4.7, \mathrm{CaCl}_{2} 2.5, \mathrm{MgSO}_{4} 1.2, \mathrm{NaHCO}_{3} 25, \mathrm{KHPO}_{4}$ 1.2 and glucose 8.3) and atrial and ventricular trabeculae ( $<1 \mathrm{~mm}$ thickness) were carefully dissected free. The trabeculae were mounted in organ baths containing Krebs buffer (gassed with $95 \% \mathrm{O}_{2}$ and $5 \% \mathrm{CO}_{2}$; $37^{\circ} \mathrm{C}$ ) and isometric tension was recorded with a Harvard transducer. Resting tension was set to 750 and $1950 \mathrm{mg}$ for atrial and ventricular tissues, respectively, in order to provide optimal loading conditions. Tissues were paced at $1 \mathrm{~Hz}$, using electrical field stimulation (3 ms, voltage $20 \%$ above threshold).

\subsection{Experimental protocols}

\section{In vivo experiments}

After a 45-min stabilization period, the animals were assigned at random to treatment (intracarotid infusions) with either saline ( 4 times, $125 \mu \mathrm{l} / \mathrm{min}, n=8$ ) or human $\alpha$-CGRP $(10,30$ and $100 \mathrm{pmol} / \mathrm{kg} \cdot \min , n=8)$. Each dose was infused for $10 \mathrm{~min}$ to obtain stable blood flow signals. At baseline and after each infusion period, haemodynamic variables were collected and radioactive microspheres were injected. After the highest dose of human $\alpha$-CGRP $(100 \mathrm{pmol} / \mathrm{kg} \cdot \mathrm{min})$, infusion was continued and either dihydroergotamine (100 $\mu \mathrm{g} / \mathrm{kg}$ i.v.; $n=4)$ or sumatriptan $(300 \mu \mathrm{g} / \mathrm{kg}$ i.v.; $n=4$ ) was injected and all variables were reassessed after $10 \mathrm{~min}$.

\section{In vitro experiments}

Baseline force of contraction was measured after stabilization, and inotropic responsiveness was assessed by making a concentration-response curve for noradrenaline $\left(10^{-8}-10^{-5} \mathrm{M}\right)$. The maximum concentration of noradrenaline was restricted to $10^{-5} \mathrm{M}$, since tissues were irreversibly damaged after higher concentrations (see Schoemaker et al., 1992; Du et al., 1994). Tissues with a response to $10^{-5} \mathrm{M}$ noradrenaline smaller than $25 \mathrm{mg}$ were excluded from further analysis.

After the tissues had been washed 6 times and allowed to stabilize, a concentration-response curve for human $\alpha$-CGRP $\left(10^{-9}-10^{-7} \mathrm{M}\right)$ was obtained in both atrial and ventricular tissues. Responses to human $\alpha$-CGRP were expressed as percentages of the response to $10^{-5} \mathrm{M}$ noradrenaline. Following another wash and stabilization period of at least $10 \mathrm{~min}$, a second noradrenaline concentration-response curve was made to check the viability of the tissues.

\subsection{Data presentation and analysis}

The effect of saline and human $\alpha$-CGRP treatment in the two groups of anaesthetized pigs was analyzed by a repeated-measurement analysis of variance. When the samples represented different populations, the values after each treatment were compared to baseline values by using Duncan's new multiple range test. Subsequently, the percent changes from baseline values among groups were tested using Student's $t$-test. Baseline values for isolated atrial and ventricular tra- 
beculae were compared using an unpaired $t$-test. The effects of noradrenaline and human $\alpha$-CGRP were analyzed with an analysis of variance for repeated measurements. In all cases, statistical significance was accepted at a level of $P \leq 0.05$.

\subsection{Compounds}

The compounds used were: dihydroergotamine mesylate (Wander-Pharma, Uden, Netherlands), fentanyl citrate (Janssen Pharmaceutica, Beerse, Belgium), heparin sodium (Heparin Leo, Leo Pharmaceutical Products, Weesp, Netherlands), human $\alpha$-CGRP (Saxon Biochemicals, Hannover, Germany), ketamine $\mathrm{HCl}$ (Apharmo, Arnhem, Netherlands), midazolam (Dormicum, Roche, Mijdrecht, Netherlands), noradrenaline bitartrate (Sigma, St. Louis, MO, USA), sumatriptan (Glaxo Group Research, Ware, UK), thiopental sodium (Rhône-Poulenc Rorer, Amstelveen, Netherlands). All chemicals were dissolved in sterile saline, except fentanyl citrate which was dissolved in propylene glycol and subsequently diluted in distilled water.

\section{Results}

\subsection{Haemodynamics}

Systemic and carotid haemodynamic variables measured at baseline and after intracarotid infusions with either saline or human $\alpha$-CGRP and following injections with either sumatriptan or dihydroergotamine in the presence of human $\alpha$-CGRP infusion (100 $\mathrm{pmol} / \mathrm{kg} \cdot \mathrm{min})$ are depicted in Table 1 . No differences were observed between the two groups at baseline, and infusion of saline caused no significant change in these variables. In contrast, human $\alpha$-CGRP reduced mean arterial blood pressure with a maximum decrease of $31 \pm 4 \%(100 \mathrm{pmol} / \mathrm{kg} \cdot \mathrm{min})$. Heart rate, cardiac output and systemic vascular conductance increased dose dependently with a maximum of $78 \pm 13 \%, 44 \pm 14 \%$ and $104 \pm 8 \%$, respectively, whereas no change was observed in stroke volume. Carotid blood flow and carotid vascular conductance were enhanced following human $\alpha$-CGRP with a maximum increase of $199 \pm$ $46 \%(30 \mathrm{pmol} / \mathrm{kg} \cdot \mathrm{min})$ and $277 \pm 58 \%(100 \mathrm{pmol} / \mathrm{kg}$ - min), respectively (Fig. 1; Table 1 ). Together with the

Table 1

Systemic and carotid haemodynamic variables measured at baseline and after intracarotid infusions of either saline (control; $n=8$ ) or human $\alpha$-CGRP ( $n=8$ ) and following injections of either sumatriptan (SUM, $300 \mu \mathrm{g} / \mathrm{kg}$ i.v.; $n=4)$ or dihydroergotamine (DHE, $100 \mu \mathrm{g} / \mathrm{kg}$ i.v.; $n=4)$ in the presence of human $\alpha$-CGRP $(100 \mathrm{pmol} / \mathrm{kg} \cdot \mathrm{min})$

\begin{tabular}{|c|c|c|c|c|c|c|c|}
\hline & \multicolumn{7}{|c|}{ Saline or human $\alpha$-CGRP $(\mathrm{pmol} / \mathrm{kg} \cdot \min )$} \\
\hline & Baseline & 10 & & 30 & 100 & $100+$ SUM & $100+$ DHE \\
\hline \multicolumn{8}{|c|}{$M A P(m m ~ H g)$} \\
\hline Saline & $86 \pm 4$ & 83 & \pm 4 & $85 \pm 4$ & $85 \pm 4$ & $84 \pm 4$ & - \\
\hline$\alpha$-CGRP & $89 \pm 2$ & 86 & \pm 2 & $76 \pm 3^{a}$ & $61 \pm 3^{a}$ & $49 \pm 5^{\dagger}$ & $52 \pm 4$ \\
\hline \multicolumn{8}{|c|}{$H R$ (beats / $\min )$} \\
\hline Saline & $76 \pm 6$ & 74 & \pm 5 & $74 \pm 6$ & $75 \pm 5$ & $74 \pm 6$ & - \\
\hline$\alpha$-CGRP & $80 \pm 10$ & 90 & \pm 11 & $104 \pm 9^{a}$ & $139 \pm 13^{a}$ & $114 \pm 24$ & $134 \pm 18$ \\
\hline \multicolumn{8}{|c|}{$C O(l / \min )$} \\
\hline Saline & $1.3 \pm 0.1$ & & \pm 0.1 & $1.3 \pm 0.1$ & $1.3 \pm 0.1$ & $1.4 \pm 0.2$ & - \\
\hline \multicolumn{7}{|l|}{$S V(m l)$} & $1.6 \pm 0.2$ \\
\hline Saline & $18 \pm 0.8$ & 18 & \pm 0.8 & $18 \pm 0.7$ & $18 \pm 0.8$ & $19 \pm 1.0$ & - \\
\hline$\alpha$-CGRP & $18 \pm 1.5$ & 19 & \pm 1.7 & $18 \pm 1.7$ & $15 \pm 2.4$ & $15 \pm 3.0$ & $13 \pm 3.0$ \\
\hline \multicolumn{8}{|c|}{$\mathrm{SVC}(\mathrm{ml} / \mathrm{min} \cdot \mathrm{mm} \mathrm{Hg})$} \\
\hline Saline & $16 \pm 1$ & 16 & \pm 1 & $16 \pm 1$ & $16 \pm 1$ & $16 \pm 2$ & - \\
\hline$\alpha$-CGRP & $15 \pm 1$ & 19 & \pm 2 & $25 \pm 2^{a}$ & $31 \pm 2^{a}$ & $31 \pm 1$ & $31 \pm 1$ \\
\hline \multicolumn{8}{|c|}{$C V C(m l / \min \cdot m m ~ H g)$} \\
\hline Saline & $60 \pm 8$ & 66 & \pm 9 & $67 \pm 12$ & $70 \pm 10$ & $64 \pm 4$ & - \\
\hline$\alpha$-CGRP & $58 \pm 4$ & 118 & $\pm 13^{a}$ & $193 \pm 18^{a}$ & $207 \pm 20^{\mathrm{a}}$ & $165 \pm 21^{b}$ & $145 \pm 23^{b}$ \\
\hline \multicolumn{8}{|c|}{$C F P(m l / \min )$} \\
\hline Saline & $47 \pm 10$ & 46 & \pm 11 & $45 \pm 9$ & $45 \pm 8$ & $47 \pm 9$ & - \\
\hline$\alpha$-CGRP & $67 \pm 7$ & 74 & \pm 6 & $108 \pm 9^{a}$ & $159 \pm 16^{a}$ & $148 \pm 7$ & $181 \pm 34$ \\
\hline
\end{tabular}

Values represent means \pm S.E.M.; ${ }^{a} P \leq 0.05$ versus saline; ${ }^{b} P \leq 0.05$ versus human $\alpha$-CGRP $(100 \mathrm{pmol} / \mathrm{kg} \cdot \min )$. HR, heart rate; MAP, mean arterial blood pressure; $\mathrm{CO}$, cardiac output; SV, stroke volume; SVC, systemic vascular conductance; CVC, carotid vascular conductance; CFP, carotid flow pulse. 
enhanced carotid blood flow, a significant increase in vascular pulse amplitude was observed with human $\alpha$-CGRP, 30 and $100 \mathrm{pmol} / \mathrm{kg} \cdot \mathrm{min}$; maximum increase from baseline $142 \pm 19 \%$ (Table 1).

Intravenous injections of either sumatriptan (300 $\mu \mathrm{g} / \mathrm{kg})$ or dihydroergotamine $(100 \mu \mathrm{g} / \mathrm{kg})$ in the presence of intracarotid infusions of human $\alpha$-CGRP (100 $\mathrm{pmol} / \mathrm{kg} \cdot \mathrm{min})$ reduced mean arterial blood pressure by $42 \pm 5 \%$ and $33 \pm 5 \%$, respectively, but induced no further change in the other systemic haemodynamic variables (Table 1). Both carotid blood flow and carotid vascular conductance were reduced by sumatriptan ( 42 $\pm 3 \%$ and $23 \pm 6 \%$, respectively) and dihydroergotamine (33 $\pm 5 \%$ and $26 \pm 4 \%$, respectively) (Fig. 1; Table 1). Carotid flow pulse remained stable following either drug (Table 1).

\subsection{Carotid blood flow distribution}

The human $\alpha$-CGRP-induced increase in carotid blood flow was confined to the capillary fraction, which was increased from baseline $(41 \pm 4 \mathrm{ml} / \mathrm{min})$ by $237 \pm$ $45 \%(30 \mathrm{pmol} / \mathrm{kg} \cdot \mathrm{min})$. At baseline, $21 \pm 5 \%(n=16)$ of the total carotid blood flow was directed towards arteriovenous anastomoses and no differences were

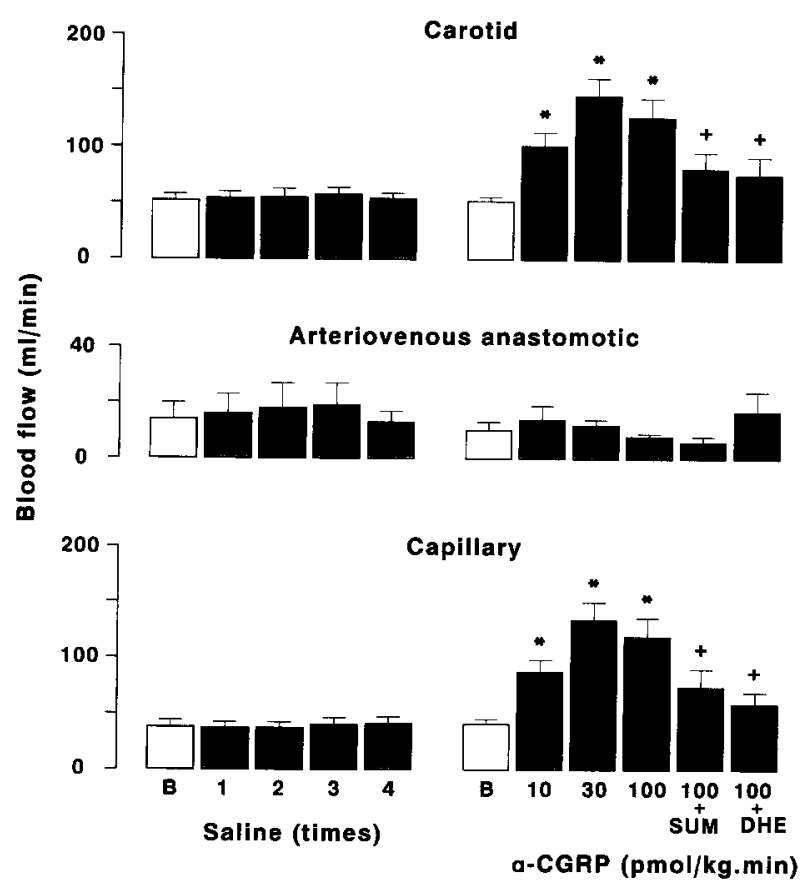

Fig. 1. Carotid blood flow and its distribution over arteriovenous anastomotic and capillary fractions at baseline (B) and after intracarotid infusions of saline (4 times, $n=8$; left panels) or human $\alpha$-CGRP $(10,30$ and $100 \mathrm{pmol} / \mathrm{kg} \cdot \mathrm{min}, n=8$; right panels), followed by either sumatriptan (SUM; $300 \mu \mathrm{g} / \mathrm{kg}$ i.v.; $n=4$ ) or dihydroergotamine (DHE; $100 \mu \mathrm{g} / \mathrm{kg}$ i.v.; $n=4$ ) in the presence of human $\alpha$-CGRP $(100 \mathrm{pmol} / \mathrm{kg} \cdot \mathrm{min})$. Values represent means \pm S.E.M.; ${ }^{*} P$ $\leq 0.05$ versus saline values; ${ }^{+} P \leq 0.05$ versus human $\alpha$-CGRP.

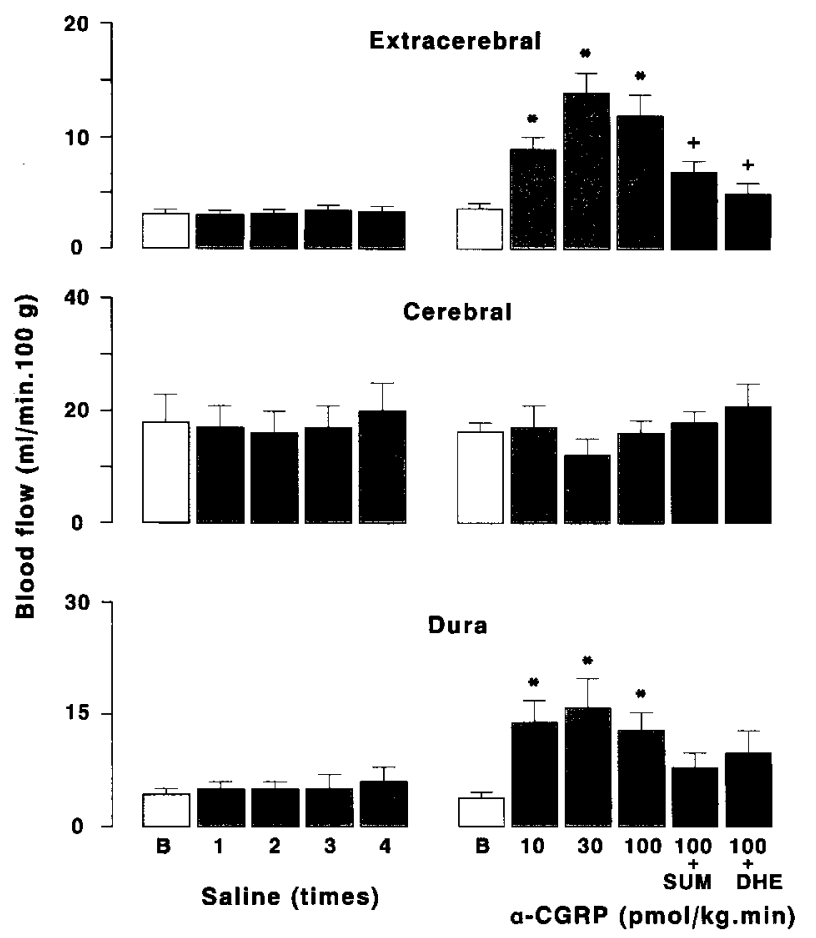

Fig. 2. Tissue blood flow distribution over extracerebral and cerebral tissues at baseline (B) and after intracarotid infusions of saline (4 times, $n=8$; left panels) or human $\alpha$-CGRP (10, 30 and 100 $\mathrm{pmol} / \mathrm{kg} \cdot \min , n=8$; right panels), followed by either sumatriptan (SUM; $300 \mu \mathrm{g} / \mathrm{kg}$ i.v.; $n=4$ ) or dihydroergotamine (DHE; 100 $\mu \mathrm{g} / \mathrm{kg}$ i.v.; $n=4)$ in the presence of human $\alpha$-CGRP $(100 \mathrm{pmol} / \mathrm{kg}$. min). Values represent means \pm S.E.M.; ${ }^{*} P \leq 0.05$ versus saline values; ${ }^{+} P \leq 0.05$ versus human $\alpha$-CGRP.

observed between the two groups. Neither saline nor human $\alpha$-CGRP induced changes in the arteriovenous anastomotic fraction (Fig. 1). Likewise, the increase in carotid vascular conductance was reflected by an increase in capillary conductance, which increased from baseline $(46 \pm 4 \mathrm{ml} / \mathrm{min} \cdot \mathrm{mm} \mathrm{Hg})$ to a maximum of $330 \pm 57 \%$ (data not shown). Sumatriptan and dihydroergotamine reduced equally the human $\alpha$-CGRPinduced increase in capillary blood flow by $42 \pm 4 \%$ and $44 \pm 5 \%$, respectively, whereas neither drug affected arteriovenous anastomotic blood flow (Fig. 1). Similarly, sumatriptan and dihydroergotamine reduced capillary conductance by $23 \pm 6 \%$ and $38 \pm 5 \%$, respectively, without changing arteriovenous anastomotic conductance (data not shown).

Human $\alpha$-CGRP enhanced tissue blood flow dose dependently in extracerebral tissues by $308 \pm 49 \%$ (30 $\mathrm{pmol} / \mathrm{kg} \cdot \mathrm{min}$ ) without changing total brain blood flow. In cranial tissues, dural blood flow was increased dose dependently from baseline $(4.0 \pm 0.8 \mathrm{ml} / \mathrm{min} \cdot 100 \mathrm{~g})$ to a maximum of $367 \pm 111 \%$ (Fig. 2). Tissue blood flow was significantly enhanced in all extracranial tissues, including the bones, ears, eyes, fat, muscles, salivary glands, skin and tongue (Fig. 3). Major increases 


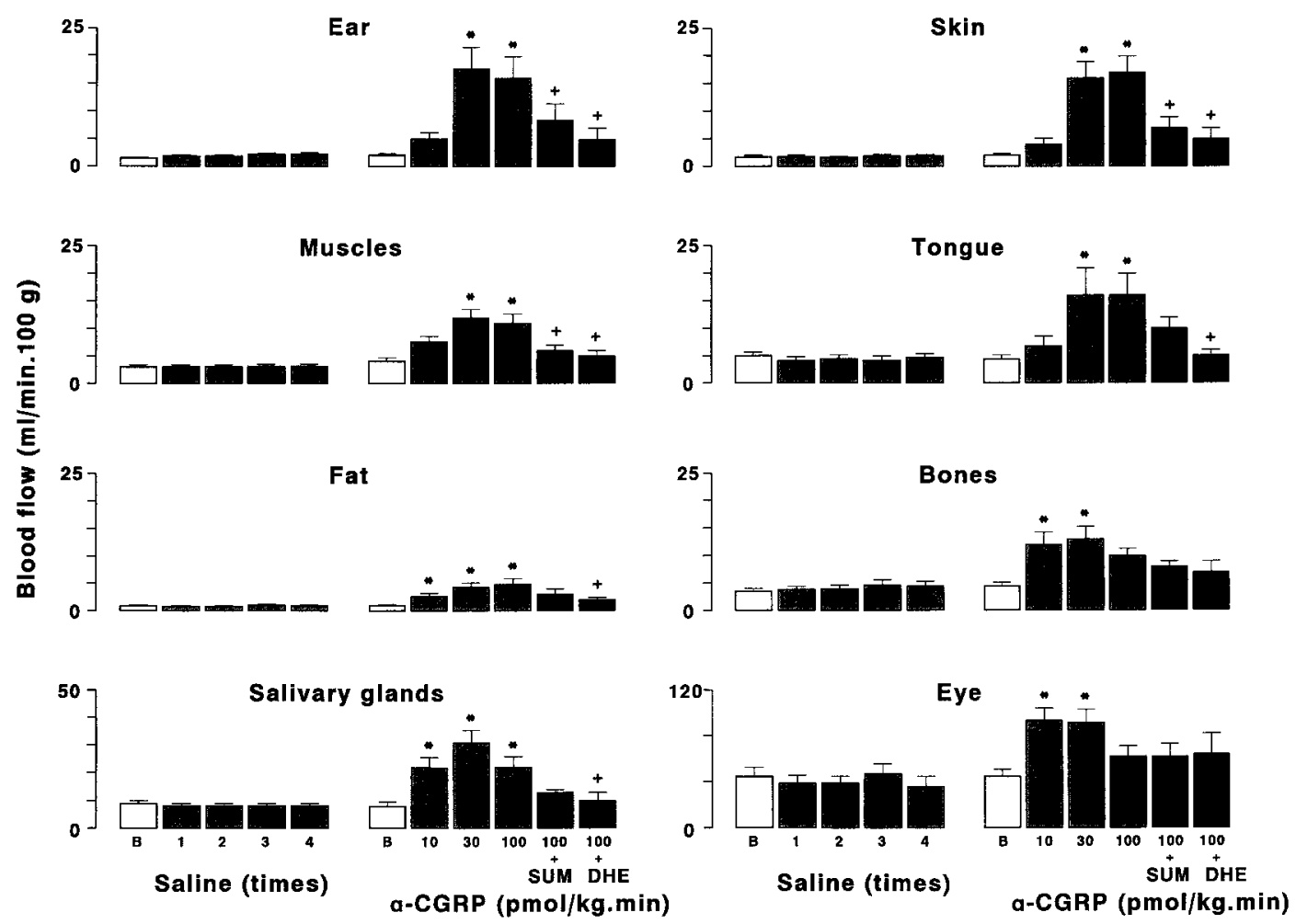

Fig. 3. Tissue blood flow to extracerebral tissues at baseline (B) and after intracarotid infusions of saline (4 times, $n=8$; left panels) or human $\alpha$-CGRP $(10,30$ and $100 \mathrm{pmol} / \mathrm{kg} \cdot \min , n=8$; right panels), followed by either sumatriptan (SUM; $300 \mu \mathrm{g} / \mathrm{kg}$ i.v.; $n=4)$ or dihydroergotamine (DHE; $100 \mu \mathrm{g} / \mathrm{kg}$ i.v.; $n=4)$ in the presence of human $\alpha$-CGRP $(100 \mathrm{pmol} / \mathrm{kg} \cdot \min )$. Values represent means $\pm \mathrm{S}$.E.M.; ${ }^{*} P \leq 0.05 \mathrm{versus}$ saline values; ${ }^{+} P \leq 0.05$ versus human $\alpha$-CGRP.

were observed in the ears and skin, with a maximum increase of $802 \pm 198 \%$ and $808 \pm 160 \%$, respectively (Fig. 3).

Sumatriptan and dihydroergotamine reversed human $\alpha$-CGRP-induced increases in extracerebral blood flow by $44 \pm 4 \%$ and $49 \pm 4 \%$, respectively. In tissues, dural blood flow was slightly reduced by both drugs (Fig. 2). The two drugs partially reversed the increases in blood flow in the ears, skin and muscles, without affecting that to the bones and eyes (Fig. 3). Additionally, dihydroergotamine reversed blood flow increases in the tongue, salivary glands and fat (Fig. 3).

\subsection{Myocardial contractility in vitro}

Baseline force of contraction was significantly lower in atrial tissue $(50 \pm 16 \mathrm{mg}, n=6)$ than in ventricular tissue $(595 \pm 137 \mathrm{mg}, n=10)$. As shown in Fig. 4, noradrenaline $\left(10^{-8}-10^{-5} \mathrm{M}\right)$ increased force of contraction in a concentration-dependent manner in both tissues. With the highest concentration of noradrenaline $\left(10^{-5} \mathrm{M}\right)$, the force of contraction increased by $163 \pm 50 \mathrm{mg}(n=6)$ and $615 \pm 106 \mathrm{mg}(n=10)$ in atrial and ventricular trabeculae, respectively. At the

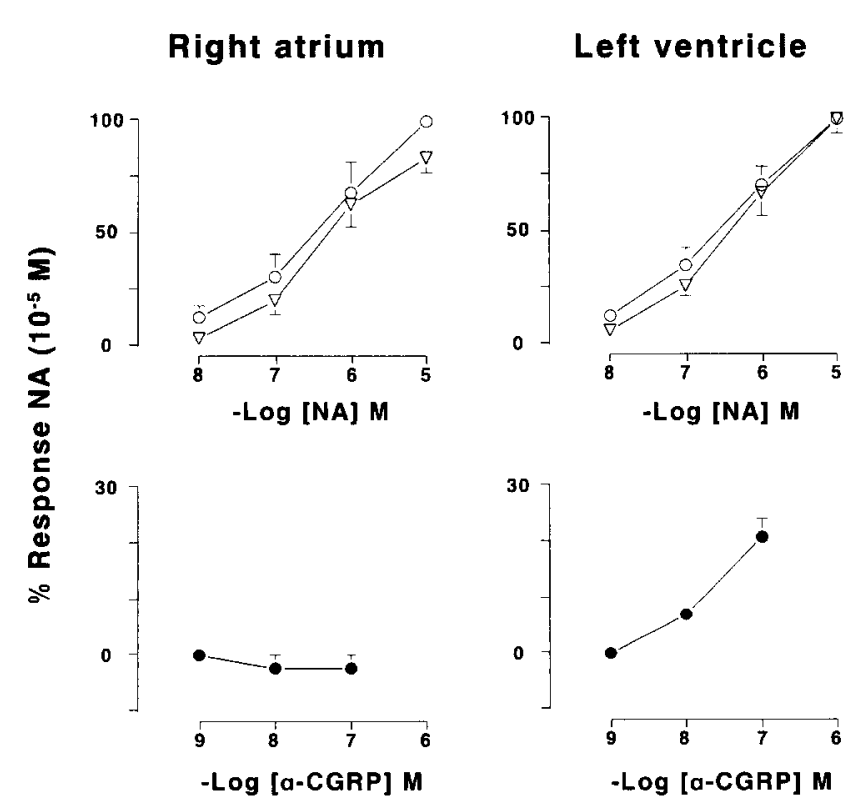

Fig. 4. Concentration-response curves for noradrenaline (NA; upper panels) (first: $O$, second: $\nabla$ ) and $\alpha$-CGRP ( $\bullet$; lower panels) in porcine isolated right atrial $(n=6)$ and left ventricular $(n=10)$ trabeculae. Responses are expressed as percentages of the response to NA $\left(10^{-5} \mathrm{M}\right)$ at baseline. Values represent means \pm S.E.M. 
end of the protocol, noradrenaline $\left(10^{-5} \mathrm{M}\right)$ induced positive inotropic responses comparable to the initial responses in ventricular trabeculae $(100 \pm 6 \%, n=10)$ whereas noradrenaline responses in atrial trabeculae were slightly reduced $(84 \pm 7 \%, n=6)$ (Fig. 4).

In contrast to noradrenaline, human $\alpha$-CGRP $\left(10^{-9}-10^{-7} \mathrm{M}\right)$ failed to increase force of contraction in the atrial tissue (baseline: $107 \pm 26 \mathrm{mg}, 10^{-7} \mathrm{M}$ human $\alpha$-CGRP: $103 \pm 25 \mathrm{mg} ; n=6$ each), but exerted a moderate concentration-dependent positive inotropic effect in ventricular tissue (Fig. 4). At $10^{-7} \mathrm{M}$ human $\alpha$-CGRP, ventricular contractile force increased from $545 \pm 110 \mathrm{mg}$ at baseline up to $663 \pm 120$ $\mathrm{mg}$, or $21 \pm 3 \%$ of the response to $10^{-5} \mathrm{M}$ noradrenaline $(n=10)$.

\section{Discussion}

\subsection{Systemic haemodynamics}

The systemic haemodynamic effects of human $\alpha$ CGRP have been described extensively in animals and humans (Franco-Cereceda et al., 1987; Lappe et al., 1987; Gardiner et al., 1989, 1991; Wang et al., 1989). The fall in systemic blood pressure and increase in systemic vascular conductance observed with intracarotid infusions of the two highest concentrations (30 and $100 \mathrm{pmol} / \mathrm{kg} \cdot \mathrm{min}$ ) of human $\alpha$-CGRP are in accordance with these reports, but also show that the potent vasodilator action of the peptide was not limited to the carotid circulation. Since heart rate increased in parallel with the decline in blood pressure, it is reasonable to assume that changes in heart rate were baroreflex-mediated. Our unpublished observations in two pigs, anaesthetized with pentobarbital and subjected to bilateral vagosympathectomy, support this view; intracarotid infusions of human $\alpha$-CGRP (up to 100 $\mathrm{pmol} / \mathrm{kg} \cdot \mathrm{min})$ in these animals with markedly inhibited sympathetic tone (see Den Boer et al., 1993) did not increase heart rate, despite a pronounced fall in arterial pressure. It, however, remains possible that in other circumstances (e.g. the use of porcine $\alpha$-CGRP in pigs) or in other species additional mechanisms, such as a direct chronotropic action or release of catecholamines, may contribute to the observed tachycardia. Indeed, heart rate responses to $\alpha$-CGRP were attenuated but not completely abolished in dogs after cardiac denervation (Wang et al., 1989). A direct chronotropic effect of rat $\alpha$-CGRP has also been observed in rat isolated atria (Sigrist et al., 1986), but no tachycardia was detected in conscious rats given human $\alpha$-CGRP (Gardiner et al., 1989). On the other hand, catecholamine release was reported in dogs and man (Franco-Cereceda et al., 1987; Wang et al., 1989), and $\beta$-adrenoceptor blockade abolished tachycardia in cardiac denervated dogs (Wang et al., 1989).
As previously reported for rats (Lappe et al., 1987), cardiac output increased without changes in stroke volume, most likely, reflecting a reduction in afterload, as indicated by the fall in systemic blood pressure. However, when systemically infused in a comparable dose, human $\alpha$-CGRP enhanced indices of contractility in conscious rats, despite a marked reduction in stroke index, possibly due to the reduction in venous pressure (Gardiner et al., 1991). If this was also the case in our experiments, the putative positive inotropic action of human $\alpha$-CGRP (see Section 4.3) was masked in pigs by concomitant venodilatation.

Both dihydroergotamine and sumatriptan failed to reverse human $\alpha$-CGRP-induced systemic haemodynamic changes. Either drug tended to reduce mean arterial blood pressure, significantly so only in the case of sumatriptan. Since the latter was shown previously to reduce cardiac output in anaesthetized pigs (Den Boer et al., 1992b), the small change in this variable may have accounted for the additional reduction in blood pressure. As no significant changes in systemic vascular conductance were observed with either dihydroergotamine or sumatriptan, both drugs exerted a selective vasoconstrictor effect in the carotid vasculature.

\subsection{Carotid haemodynamics}

\section{Carotid vascular pulsations}

The increase in carotid vascular pulsations caused by human $\alpha$-CGRP is partially in accord with previous observations using Doppler flow measurements in humans, when the peptide enhanced pulsatility in the internal carotid artery, but not in the common carotid artery (MacDonald et al., 1989). As argued before, these increased pulsations most likely reflect changes in vascular compliance following vasodilatation, though the precise mechanism is unclear (Van Gelderen et al., 1995). It is to be noted that local pulsatile flow may be influenced by changes in systemic vascular resistance and, furthermore, similar changes in pulsatility are also observed with histamine and nitrovasodilators, precluding the existence of a specific mechanism (Graham and Wolff, 1938; Thomsen et al., 1993; Van Gelderen et al., 1995). The inability of either dihydroergotamine or sumatriptan to change the carotid vascular pulsations induced by human $\alpha$-CGRP may argue against vasodilatation as the sole underlying mechanism. Additionally, it is possible that the dose of the antimigraine drugs was not sufficient to oppose the enhanced vascular pulsations during continued infusion of a high dose of human $\alpha$-CGRP.

\section{Carotid blood flow distribution}

In keeping with the observations in rats (Gardiner et al., 1989, 1991), human $\alpha$-CGRP elevated common 
carotid blood flow dose dependently, associated with pronounced increases in regional tissue blood flow, indicating arteriolar dilatation. In the presence of a high concentration of human $\alpha$-CGRP, sumatriptan and dihydroergotamine reduced carotid blood flow to an extent similar to that reported in the absence of the peptide (Den Boer et al., 1992a), suggesting that their vasoconstrictor action in this vessel does not depend on the level of circulating human $\alpha$-CGRP.

As previously reported (Den Boer et al., 1993; Van Gelderen et al., 1995), approximately $21 \%$ of the carotid blood flow (compared to over $70 \%$ in anaesthetized pigs, Den Boer et al., 1992a) was shunted through arteriovenous anastomoses, indicating that, at baseline, these vessels were largely under sympathetic constrictor tone. Despite its potent vasodilator action, human $\alpha$-CGRP failed to affect blood flow through arteriovenous anastomoses. These vessels appear to be innervated by sensory nerves (Gorgas et al., 1977; Hales and Molyneux, 1988) and CGRP-containing fibres have been demonstrated immunohistochemically in the proximity of arteriovenous anastomoses in the dog tongue (Hino et al., 1993). Moreover, in a similar dose, CGRP increased arteriovenous anastomoses blood flow in the sheep hind limb (Mogg et al., 1992). The lack of effect of human $\alpha$-CGRP in our study is not explained by the difference in peptide used (human $\alpha$-CGRP versus rat CGRP), since more pronounced vasodilator effects have been reported with human $\alpha$-CGRP than with rat $\alpha$-CGRP (Gardiner et al., 1989). As an elevated shunt flow was observed in the sheep hind limb, apparently without significant changes in systemic blood pressure and capillary flow (Mogg et al., 1992), it is possible that the pronounced increase in capillary blood flow in conjunction with the marked rise in systemic vascular conductance prevented the opening of arteriovenous anastomoses in the carotid circulation of the pig by way of a 'steal-like' phenomenon. As nitrovasodilators have been reported to enhance blood flow through arteriovenous anastomoses under comparable conditions (Van Gelderen et al., 1995), it seems unlikely that, in this part of the circulation, nitrovasodilators act via the release of CGRP (Wei et al., 1992; Holzer and Jočic, 1994).

The antimigraine drugs, dihydroergotamine and sumatriptan, have been shown to reduce blood flow through arteriovenous anastomoses in pigs with a high shunt flow (Den Boer et al., 1992a). Since arteriovenous anastomoses were largely closed and repeated infusions with human $\alpha$-CGRP failed to increase arteriovenous anastomotic blood fiow, such a constrictor action could not be detected in the present experiments.

In the porcine carotid circulation, human $\alpha$-CGRP increased extracerebral blood flow without affecting intracerebral flow. The predominant action on extrac- erebral tissues, most markedly reflected by the major changes in cutaneous tissues (skin and ears) supports the contention that extracranial vascular dilatation and pulsation indeed have a role in migraine headache (Graham and Wolff, 1938; Drummond and Lance, 1988). However, the absence of cerebral blood flow changes seems to be in conflict with the enhanced cerebral blood flow together with elevated CGRP levels in the external jugular vein following stimulation of the trigeminal ganglion (Goadsby and Edvinsson, 1993) as well as with the increased vessel diameter in the feline cerebral microcirculation observed with CGRP (Wei et al., 1992). This discrepancy is most likely attributable to methodological differences since, in the former study, cerebral blood flow was measured by laser Doppler flowmetry, detecting changes in large intracerebral vessels (not detected by microspheres), whereas in the latter study CGRP was applied topically, producing relatively high local concentrations. Finally, it may be argued that a putative vasodilator action of human $\alpha$-CGRP in porcine cerebral capillaries is effectively opposed by cerebral autoregulation.

Within the porcine cranial circulation, dural blood flow was significantly enhanced by human $\alpha$-CGRP. The dura mater, which is innervated by CGRP-containing nerves (Uddman et al., 1986; Suzuki et al., 1989), is regarded a likely source of headache, and plasma levels of CGRP appear to be elevated in the cranial venous effluent in migraineurs (Friberg et al., 1994). Thus, it is plausible that enhanced dural blood flow, together with increased vascular pulsatility, contributes to migraine headache. However, in spite of an increase in carotid vascular resistance indicating vasoconstriction, antimigraine drugs like dihydroergotamine and sumatriptan failed to reduce dural blood flow in pigs (Den Boer et al., 1992a), whereas sumatriptan reduced feline pial diameter only after topical application (Connor et al., 1992). Moreover, in the present study with presumably high levels of CGRP, both sumatriptan and dihydroergotamine only slightly reduced dural blood flow and failed to reduce carotid vascular pulsations.

\subsection{Myocardial contractility in vitro}

In contrast to noradrenaline, human $\alpha$-CGRP failed to increase force of contraction in porcine atrial tissue but increased contractility in ventricular tissue. So far, a positive inotropic action in the atrium rather than ventricles has been observed in the rat (Sigrist et al., 1986; Ishikawa et al., 1987), guinea pig (Saito et al., 1987) and human myocardium (Sigrist et al., 1986; Du et al., 1994), suggesting a rather uniform mode of action, at least on atrial trabeculae. However, the discrepancy may be attributable to species differences. For example, few CGRP-specific binding sites have been detected in guinea pig ventricles (Ishikawa et al., 
1988), whereas these sites could be demonstrated in porcine ventricular tissue (Miyauchi et al., 1988). At present, no data are available about specific binding sites for CGRP in the porcine atrium. The ability of human $\alpha$-CGRP to increase the force of contraction in ventricular trabeculae is in accord with the detection of binding sites for this peptide as well as with the observation of positive inotropic responses in ventricular false tendons (Miyauchi et al., 1988). Moreover, the magnitude of the inotropic response at $10^{-7} \mathrm{M}$ human CGRP, being approximately $25 \%$ of the isoprenaline control curve, was comparable with that in our study. Although these moderate ventricular inotropic responses support the hypothesis of a positive inotropic effect in anaesthetized pigs, it remains to be established whether such concentrations actually occur in vivo.

In summary and conclusion, intracarotid infusion of human $\alpha$-CGRP caused arteriolar dilatation in the pig, which was accompanied by hypotension, tachycardia and an increase in cardiac output. Within the carotid circulation, vasodilatation was largely confined to extracerebral tissues and the marked increase in capillary blood flow together with the fall in systemic blood pressure most likely prevented the opening of arteriovenous anastomoses. Furthermore, in the presence of high levels of human $\alpha$-CGRP, the antimigraine drugs, dihydroergotamine and sumatriptan, reversed blood flow changes induced by human $\alpha$-CGRP in extracerebral tissues.

\section{Acknowledgements}

The authors appreciate the skilful technical assistance of Mr. J.P.C. Heiligers.

\section{References}

Brain, S.D., T.J. Williams, J.R. Tippins, H.R. Morris and I. Maclntyre, 1985, Calcitonin gene-related peptide is a potent vasodilator, Nature 313, 54.

Connor, H.E, C.M. Stubbs, W. Feniuk and P.P.A. Humphrey, 1992,

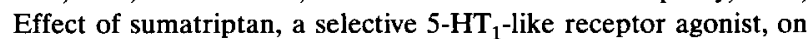
pial vessel diameter in anaesthetized cats, J. Cereb. Blood Flow Metab. 12, 514.

Den Boer, M.O., J.A.E. Somers and P.R. Saxena, 1992a, Lack of effect of the antimigraine drugs sumatriptan, ergotamine and dihydroergotamine on arteriovenous anastomotic shunting in the dura mater of the pig, Br. J. Pharmacol. 107, 577.

Den Boer, M.O., J.A.E. Somers and P.R. Saxena, 1992b, Comparative effects of the antimigraine drugs sumatriptan and ergotamine on the distribution of cardiac output in anaesthetized pigs, Cephalalgia 12, 206.

Den Boer, M.O., L.J. Van Woerkens, J.A.E. Somers, D.J. Duncker, B. Lachmann, P.R. Saxena and P.D. Verdouw, 1993, On the preservation and regulation of vascular tone in arteriovenous anastomoses during anesthesia, J. Appl. Physiol. 75, 782.
Drummond, P.D. and J.W. Lance, 1988, Contribution of the extracranial circulation to the pathophysiology of headache, in: Basic Mechanisms of Headache, eds J. Olesen and L. Edvinsson (Elsevier, Amsterdam) p. 321.

Du, X.Y., R.G. Schoemaker, E. Bos and P.R. Saxena, 1994, Different pharmacological responses of atrium and ventricle: studies with human cardiac tissue, Eur. J. Pharmacol. 259, 173.

Ferrari, M.D. and P.R. Saxena, 1993, Clinical and experimental effects of sumatriptan in humans, Trends Pharmacol. Sci. 14, 129.

Franco-Cereceda, A., C. Gennari, R. Nami, D. Agnusdei, J. Pernow, J.M. Lundberg and J.A. Fischer, 1987, Cardiovascular effects of calcitonin gene-related peptides I and II in Man, Circ. Res. 60, 393.

Friberg, L., J. Olesen, T. Skyhøj Olsen, A. Karle, R. Ekman and J. Fahrenkrug, 1994, Absence of vasoactive peptide release from brain to cerebral circulation during onset of migraine with aura, Cephalalgia 14, 47.

Gardiner, S.M., A.M. Compton and T. Bennett, 1989, Regional haemodynamic effects of human $\alpha$ - and $\beta$-calcitonin gene-related peptide in conscious wistar rats, Br. J. Pharmacol. 98, 1225.

Gardiner, S.M., A.M. Compton, P.A. Kemp, T. Bennett, B. Hughes and R. Foulkes, 1991, Differential effects of $( \pm)$-dobutamine and human $\alpha$-CGRP on cardiac and on regional haemodynamics in conscious Long Evans rats, Br. J. Pharmacol. 103, 1509.

Goadsby, P.J. and L. Edvinsson, 1993, The trigeminovascular system and migraine: studies characterizing cerebrovascular and neuropeptide changes seen in humans and cats, Ann. Neurol. 33, 48.

Goadsby, P.J., L. Edvinsson and R. Ekman, 1990, Vasoactive peptide release in the extracerebral circulation of humans during migraine headache, Ann. Neurol. 28, 183.

Gorgas, K., P. Böck, F. Tischendorf and S.B. Curri, 1977, The fine structure of human arterio-venous anastomoses (Hoyer-Grosser's organs), Anat. Embryol. 150, 269.

Graham, J.R. and H.G. Wolff, 1938, Mechanism of migraine headache and action of ergotamine tartrate, Arch. Neurol. Psychiatry $39,737$.

Hales, J.R.S. and G.S. Molyneux, 1988, Control of cutaneous arteriovenous anastomoses, in: Vasodilatation: Vascular Smooth Muscle, Peptides, Autonomic Nerves and Endothelium, ed P.M. Vanhoutte (Raven Press, New York) p. 321.

Hino, N., S. Masuko and T. Katsuki, 1993, An immunohistochemical study of sensory and autonomic innervation of the dog tongue with special reference to substance P-and calcitonin gene-related peptide-containing fibres in blood vessels and the intralingual ganglia, Arch. Histol. Cytol. 56, 505.

Holzer, P. and M. Jočic, 1994, Cutaneous vasodilatation induced by nitric oxide-evoked stimulation of afferent nerves in the rat, $\mathrm{Br}$. J. Pharmacol. 112, 1181.

Ignarro, L.J., 1990, Biosynthesis and metabolism of endothelium-derived nitric oxide, Annu. Rev. Pharmacol. Toxicol. 30, 535.

Ishikawa, T., N. Okamura, A. Saito and K. Goto, 1987, Effects of calcitonin gene-related peptide (CGRP) and isoproterenol on the contractility and adenylate cyclase activity in the rat heart, J. Mol. Cell. Cardiol. 19, 723.

Ishikawa, T., N. Okamura, A. Saito, T. Masaki and K. Goto, 1988, Positive inotropic effect of calcitonin gene-related peptide mediated by cyclic AMP in guinea pig heart, Circ. Res. 63, 726.

Johnston, B.M. and P.R. Saxena, 1978, The effect of ergotamine on tissue blood flow and the arteriovenous shunting of radioactive microspheres in the head, Br. J. Pharmacol. 63, 541.

Lappe, R.W., M.J. Slivjak, J.A. Todt and R.L. Wendt, 1987, Hemodynamic effects of calcitonin gene-related peptide in conscious rats, Regul. Pept. 19, 307.

MacDonald, N.J., L. Butters, D.J. O'Shaughnessy, A.J. Riddel and P.C. Rubin, 1989, A comparison of the effects of human alpha calcitonin gene-related peptide and glyceryl trinitrate on regional blood velocity in man, Br. J. Clin. Pharmacol. 28, 257. 
Miyauchi, T., Y. Sano, O. Hiroshima, T. Yuzuriha, Y. Sugishita, T. Ishikawa, A. Saito and K. Goto, 1988, Positive inotropic effects and receptors of calcitonin gene-related peptide (CGRP) in porcine ventricular muscles, Biochem. Biophys. Res. Commun. $155,289$.

Mogg, K.C., J.R.S. Hales, A.A Fawcett and C.C. Pollitt, 1992, Controversial influences of peptides on AVA and capillary blood flow in the sheep limb, in: The Pathophysiological Basis of Clinical Disorders, eds. P. Lomax and E. Schönbaum (Karger, Basel) p. 124.

Mulderry, P.K., M.A. Ghatei, J. Rodrigo, J.M. Allen, M.G. Rosenfeld, J.M. Polak and S.R. Bloom, 1985, Calcitonin gene-related peptide in cardiovascular tissues of the rat, Neuroscience 14, 947.

Olesen, J., H.K. Iversen and L.L. Thomsen, 1993, Nitric oxide supersensitivity: a possible molecular mechanism of migraine pain, Neuroreport 4, 1027.

Saito, A., T. Ishikawa, S. Kimura and K. Goto, 1987, Role of calcitonin gene-related peptide as cardiotonic neurotransmitter in guinea pig left atria, J. Pharmacol. Exp. Ther. 243, 731.

Saxena, P.R., 1978, Arteriovenous shunting and migraine, Res. Clin. Stud. Headache 6, 89.

Saxena, P.R. and P.D. Verdouw, 1982, Redistribution by 5-hydroxytryptamine of carotid arterial blood at the expense of arteriovenous anastomotic blood flow, J. Physiol. (London) 332, 501.

Saxena, P.R., H.C. Schamhardt, R.P. Forsyth and J. Loeve, 1980, Computer programs for the radioactive microsphere technique, Comput. Programs Biomed. 12, 63.

Schoemaker, R.G., X.Y. Du, W.A. Bax and P.R. Saxena, 1992, 5-Hydroxytryptamine increases contractile force in porcine right atrium but not in left ventricle, Naunyn-Schmied. Arch. Pharmacol. $346,486$.

Sigrist, S., A. Franco-Cereceda, R. Muff, H. Henke, J.M. Lundberg and J.A. Fischer, 1986, Specific receptor and cardiovascular effects of calcitonin gene-related peptide, Endocrinology 119, 381 .

Suzuki, N., J.E. Hardebo and Ch. Owman, 1989, Origins and pathways of cerebrovascular nerves storing substance $\mathbf{P}$ and calcitonin gene-related peptide in rat, Neuroscience 31, 427.

Thomsen, L.L., H.K. Iversen, T.A. Brinck and J. Olesen, 1993, Arterial supersensitivity to nitric oxide (nitroglycerin) in migraine sufferers, Cephalalgia 13, 395.

Uddman, R., L. Edvinsson, E. Ekblad, R. Håkanson and F. Sundler, 1986, Calcitonin gene-related peptide (CGRP): perivascular distribution and vasodilatory effects, Regul. Pept. 15, 1.

Van Gelderen, E.M. and P.R. Saxena, 1994, The effects of calcitonin gene-related peptide on the carotid blood flow distribution in the anaesthetized pig, Can. J. Physiol. Pharmacol. 72, 409.

Van Gelderen, E.M., E.L. De Bruijne, H.J. Agteresch and P.R. Saxena, 1995, The effect of nitric oxide donors on haemodynamics and blood flow distribution in the porcine carotid circulation, Br. J. Pharmacol. 114, 1303.

Wang, B.C., P. Bie, R.J. Leadley and K.L Goetz, 1989, Cardiovascular effects of calcitonin gene-related peptide in conscious dogs, Am. J. Physiol. 257, 726.

Wei, E.P., M.A. Moskowitz, P. Baccalini and H.A. Kontos, 1992, Calcitonin gene-related peptide mediates nitroglycerin and sodium nitroprusside-induced vasodilatation in feline cerebral arterioles, Circ. Res. 70, 1313. 